Manuel L. Romero

Vicente Albero

Ana Espinós

Antonio Hospitaler

\title{
Fire design of slim-floor beams
}

Slim-floor beams are a well-known cost-effective solution that allows for a significant floor thickness reduction, being increasingly used in industrial and commercial buildings. Additionally, by being exposed to fire only from their lower flange, slim-floor beams may achieve higher fire resistance, in contrast with other types of composite beams not fully embedded within the concrete floor. Simplified models are available in Eurocode 4 part 1-2 to evaluate the temperature distribution for partially encased and no-encased composite beams, however this standard does not provide any simplified model to evaluate the cross-sectional temperature field of the slim-floor beams. In this sense, different proposals have been evaluated during the last years in order to provide simplified models for the temperature evaluation. The currently available models in the literature have shown their accurate behavior providing safe-sided results, being recommended for its use in practice. Finally, this work shows that slim-floor composite beams can provide a good performance during a fire event. Specifically, 60 minutes of standard fire rating can be achieved for load levels lower than 0.5-0.6. Additionally, an improved behavior to achieve 90 or 120 minutes of standard fire exposure may be reached by using innovative solutions, advanced materials or external protection.

Keywords: slim-floor beams; fire resistance; fire design; simplified design methods 


\section{Introduction}

In composite construction, slim-floor beams are a well-known cost-effective solution that allows for a significant floor thickness reduction, increase of working space and ease for under-floor technical equipment installation. Owing to these advantages, slim-floor beams are being increasingly used in industrial and commercial buildings.

Slim-floor beams can be used in combination with different flooring systems, such as in-situ concrete slabs, profiled steel decks or precast concrete slabs. Moreover, the slab configuration itself changes the incidence of the thermal action to the composite beam, i.e. the hot air between the ribs in a profiled steel deck facilitates the advance of temperatures in the beam section as compared to a floor configuration with concrete slabs.

In practice, two main types of slim-floor beams can be recognized: Integrated Floor Beam (IFB, Fig. 1b) and Shallow Floor Beam (SFB, Fig. 1a). The former type is made of a half I-section where a wider bottom plate is welded to the web in replacement of the lower flange. The latter consists of a full I-section with a bottom plate attached and welded to its lower flange.

IFB
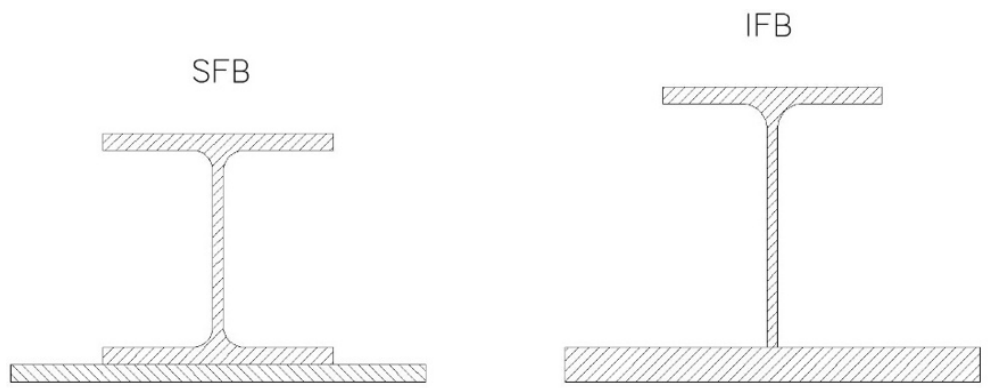

Fig. 1 Main configurations of slim-floor beam sections: a) SFB; b) IFB.

Other configurations have been made available in the construction market such as the "Thorbeam" [1] or the "Delta-beam" [2] systems developed in Scandinavia, the "Ultra Shallow Floor Beam" [3] in the UK, or more recently the shallow floor beams with small web openings (CoSFB) [4], where the composite action between steel and concrete is ensured by means of transverse reinforcing bars through the beam web openings.

Due to the fact that the steel beam is totally embedded within the concrete floor, the fire behaviour of slim-floor beams is remarkable. By being exposed to fire only from their lower flange, in contrast with other types of composite beams not fully embedded within the concrete floor, slim-floor beams can achieve higher fire resistance times. Moreover, the SFB configuration presents the additional advantage in the fire situation of a thermal gap that appears between the 
lower flange of the steel profile and the bottom plate, which delays the temperature rise of the steel profile, as observed experimentally by Newman[3]. Fellinger and Twilt [5] suggested that this thermal gap should be ensured when manufacturing SFB in order to enhance the slim-floor fire resistance.

A great number of experimental studies were carried out in the ninety's on partially encased beams under fire conditions, nevertheless the study of slim-floor beams is more recent. In particular, the flexural behaviour of slim-floor beams exposed to fire has been studied through some experimental campaigns performed over the last years [6]. Two standard fire tests were conducted by the Warrington Fire Research Center [7] with a SLIMDECK system using an IFB configuration. Significant fire resistance times of 75 and 107 minutes were achieved, for load ratios of 0.43 and 0.36 , respectively. Fire tests were also reported by Ma and Mäkeläinen [6] using an IFB configuration under different load ratios. It was observed that fire resistance periods over 60 minutes could be reached only for load ratios under 0.5 without additional fire protection.

Previous parametric studies carried out by the authors [8], [9] with a validated finite element model showed the improvement in terms of fire resistance which may be achieved through the SFB solution, as compared to an equivalent IFB configuration with the same load bearing capacity at room temperature or in terms of equal steel area. This numerical investigation confirmed that a good strategy for enhancing the fire resistance of composite beams embedded in floors is to split the lower steel flange into two steel plates. This solution creates a reduced but thermally significant gap between the lower flange and the bottom plate that delays the temperature rise and therefore lengthens the fire response of the beam.

\section{Code provisions and available fire design methods}

It is well-known that the assessment of the load-bearing capacity of any structural member during the event of a fire requires three different models: the fire model, the heat transfer model and the mechanical model at elevated temperatures.

On a first instance, the fire model involves the thermal action definition, which may be represented by nominal time-temperature curves or more sophisticated natural fire models. Usually, for construction products, the fire model is defined simply through the standard time-temperature (ISO-834) curve, which is provided in EN 1991-1-2 [10]. 
Secondly, once the thermal action is defined, the heat transfer model should provide a way to calculate the temperature field within the cross-section. While simplified models are available in EN 1994-1-2 [11] to evaluate the temperature distribution for partially encased (Annex F) and no-encased (Clause 4.3.4.2.2) composite beams, this standard does not provide any simplified heat transfer model to evaluate the temperature field of slim-floor beams.

The third stage of the fire resistance assessment is the mechanical (bending) capacity calculation at elevated temperatures, which may be addressed by means of a fiber-based model by discretizing the cross-section into a finite number of differential strips (for which the realistic temperature gradient is previously needed), or alternatively by dividing the cross-section into a number of zones with known temperatures, which allows obtaining the ultimate bending moment by "hand calculation".

In the absence of any specific method for assessing the temperature development in slim-floor beams, it is a common practice to apply the method in Annex F for partially encased composite beams with different assumptions, such as adopting an infinite width for the concrete part [12].

In this sense, different proposals have been developed during the last years in order to provide models that allow predicting the temperature field in slim-floor composite beams.

The first work worth mentioning is the model by Zaharia and Franssen [13]. This model provides detailed formulas, validated against SAFIR software, to obtain the temperature evolution of the main slim-floor beam cross-section parts. Specifically, the authors provide formulas for the assessment of the temperature at the bottom part (1), web profile and reinforcing bars (2), see Fig. 2.

$$
T=A \cdot t_{p l}^{2}+B \cdot t_{p l}+C
$$

In this equation, $\mathrm{t}_{\mathrm{pl}}$ is the bottom plate thickness in $\mathrm{mm}, \mathrm{T}$ is the temperature of the bottom part and coefficients $A, B$ and $C$ are tabulated in [13] depending on the fire exposure time, as given in Table 1.

Table 1

Coefficients for temperature calculation of the bottom part of a SFB [13]

\begin{tabular}{cccc}
\hline Time (min) & A & B & C \\
\hline 30 & 0.113 & -12.80 & 760 \\
60 & 0.130 & -11.80 & 980 \\
90 & - & -2.60 & 990 \\
120 & - & -1.25 & 1025 \\
\hline
\end{tabular}

The formulas for evaluating the temperature along the web of the steel profile and reinforcing 
bars show the following aspect:

$$
T=k \cdot e^{k^{\prime} \cdot z}
$$

where $z$ is the distance along the height of the web measured from the top of the bottom plate and $k, k$ ' are provided in [13] and depend on fire exposure time and bottom plate thickness.

It should be highlighted that these formulas were developed by taking into account the standard ISO-834 time-temperature curve as the thermal action. More details about formulas described above, which could be useful for their practical application, can be obtained in [13].

More recently, Hanus et al. [14] developed an additional simplified formula for the temperature assessment of the reinforcing bars. In this case, the formula was developed based on the temperature evolution within concrete slabs provided by EN 1992-1-2 [15], including some corrections to take into account the possible horizontal heat flux in steel-deck composite floors.

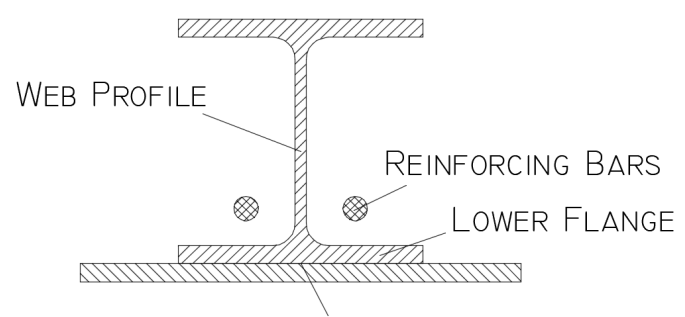

BOTTOM PLATE

Fig. 2 Shallow Floor Beam (SFB) cross-section parts

From the literature review, it was noticed that the prediction of the temperatures of the longitudinal reinforcing bars are the point where the developed thermal models mostly focus on. In fact, different models exist for the reinforcing bars temperature assessment, while for the bottom plate and web profile prediction the model from Zaharia and Franssen [13] is widely accepted. Additionally, it should be underlined that only steel parts are under evaluation into these simplified thermal models. The reason of this aspect comes from the fact that in the tension zone (i.e. the bottom part, when the cross-section is evaluated under sagging moment) only the steel parts contribute to the bending moment resistance. The tensile strength of concrete may be conservatively neglected. In turn, the compression zone, located in this case at the top part of the section, may be assumed as not affected by the fire in slim-floor beams exposed only from their lower surface.

As previously mentioned, the third model needed for the slim-floor beam assessment during fire is the mechanical model, which takes into account the evolution of the mechanical properties of 
steel and concrete at elevated temperatures. The reduction of strength and stiffness at elevated temperatures can be obtained from EN 1994-1-2 [11]. Different approaches may be used to address this mechanical calculation. The easiest one consists of the evaluation of the plastic bending resistance by splitting the cross-section into different parts composed of different materials at different representative temperatures. The plastic neutral axis position is then evaluated by means of applying the corresponding equilibrium equations and in this way the bending moment resistance can be easily obtained. An example of this methodology is exposed in the following section, where a worked example is used to illustrate its application.

\section{$3 \quad$ Advanced models}

A more precise approach to address the solution of the problem consists of the evaluation of the bending resistance through the cross-section discretization in cells, see Fig. 3. Each cell of the mesh is characterized by its position and its temperature. Using the mechanical properties at elevated temperature, the plastic bending resistance of the cross-section can be computed by applying the equilibrium equations. This methodology is very similar to the previously described one, but in this case the finer discretization of the section allows for a more accurate assessment. However, the drawback of this model is that simplified temperature formulas for different cross-section parts, cannot be used in this case. In replacement, a previous evaluation of the heat transfer problem by means of a finite differences model is needed for obtaining a detailed temperature field with the information of the temperatures of all the cross-section cells.

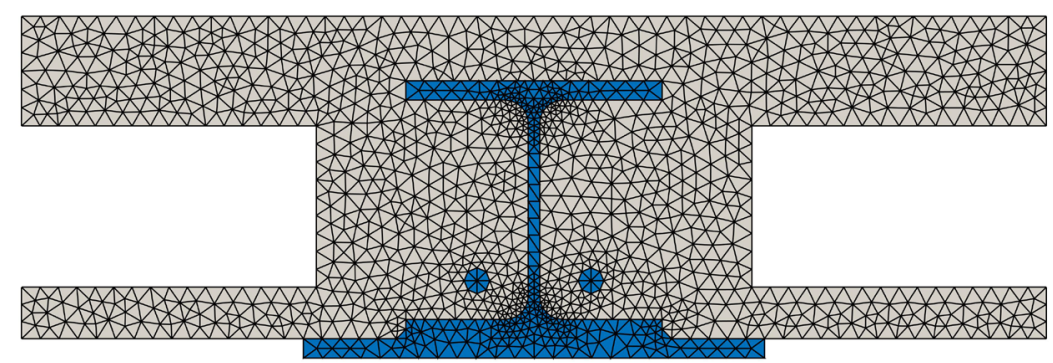

Fig. 3 Numerical model of SFB cross-section discretized in cells.

Additionally, the most sophisticated way to evaluate the thermo-mechanical behaviour of slimfloor beams is by means of finite element (FE) models. In recent investigations, some authors [16], [8] have developed detailed FE models, using ABAQUS commercial package, where a sequentially coupled thermal-stress analysis is performed (Fig. 4). The first step consists of a 
thermal analysis where the temperature field is computed. Secondly, the temperatures are imported into a mechanical FE model where the nonlinear behaviour of the materials (steel and concrete) at elevated temperatures is taken into account. For concrete and steel, the temperature dependent properties recommended in EN 1994-1-2 [11] were considered: specific heat and thermal conductivity. The upper thermal conductivity limit was used for concrete, which is a safe-sided assumption. Moreover, the mechanical properties at elevated temperatures (i.e. thermal elongation and strength reduction factors) were also considered. The stress-strain relations for steel and concrete at elevated temperatures given in EN 1994-1-2 [11] were employed.

Additionally, it is also worthy to notice that the cavity radiation model from ABAQUS was used to compute the heat transfer through the voids of the hollow core concrete slabs. This cavity model solves directly the calculation of view factors of all the element faces which adjoin the voids.

Through this type of model, other three-dimensional phenomena can be assessed, apart from the simple cross-section evaluation, such as the concrete cracking or the development of the composite effect between steel and concrete, as well as possibility of applying non-uniform heating conditions or taking into account the effect of the voids in the floor system in a more realistic way.

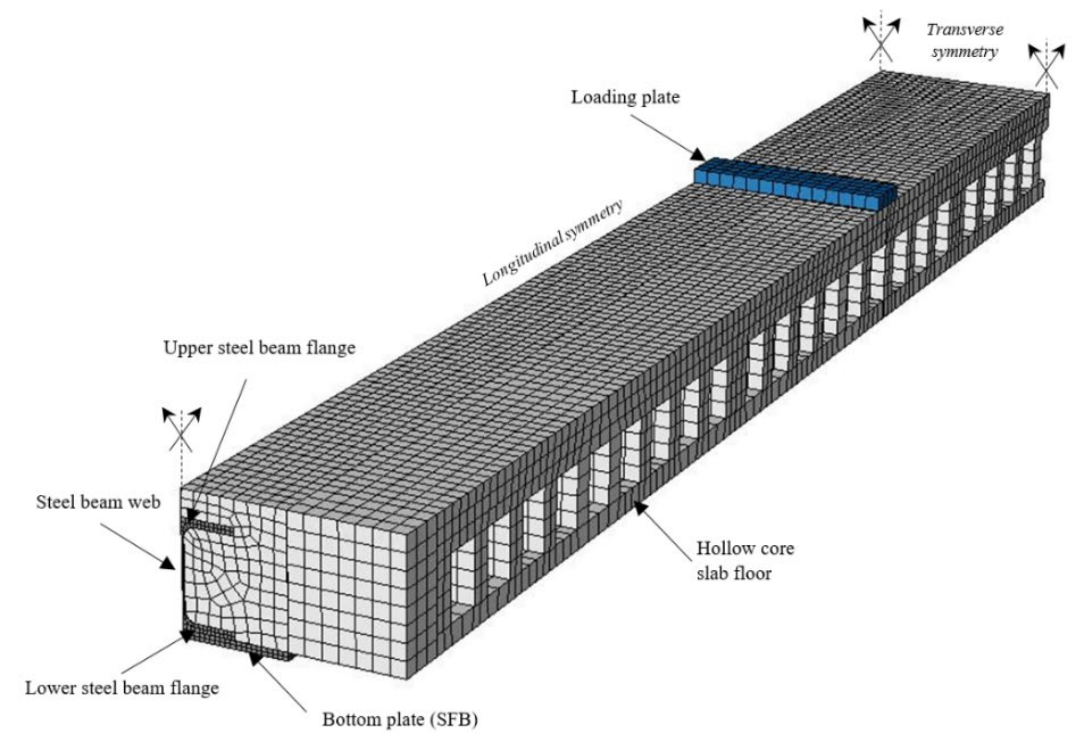

Fig. 4 FE model for slim-floor beams [8].

Once all the available models have been described, it is considered useful at this point to compare the validated FE model developed by authors [8] against the simplified temperature formulas developed by Zaharia and Franssen [13] and Hanus et al. [14]. Specifically, the bottom plate, 
the reinforcing bars and the web profile temperature evolution has been compared, see Fig. 5 and Fig. 6.

The developed FE model has been used to reproduce the thermal behaviour of a SFB crosssection made by an HEB200 profile welded to a bottom plate of $15 \mathrm{~mm}$ thickness (see Fig. 7) exposed to the standard ISO-834 time-temperature curve. In this case, the thickness of the bottom steel part will be $30 \mathrm{~mm}$ at the central position (i.e. vertical axis of the profile) and $15 \mathrm{~mm}$ at the sides. The reinforcing bars are located at $30 \mathrm{~mm}$ over the top face of the lower steel flange and at $40 \mathrm{~mm}$ horizontal distance to the web of the steel profile.

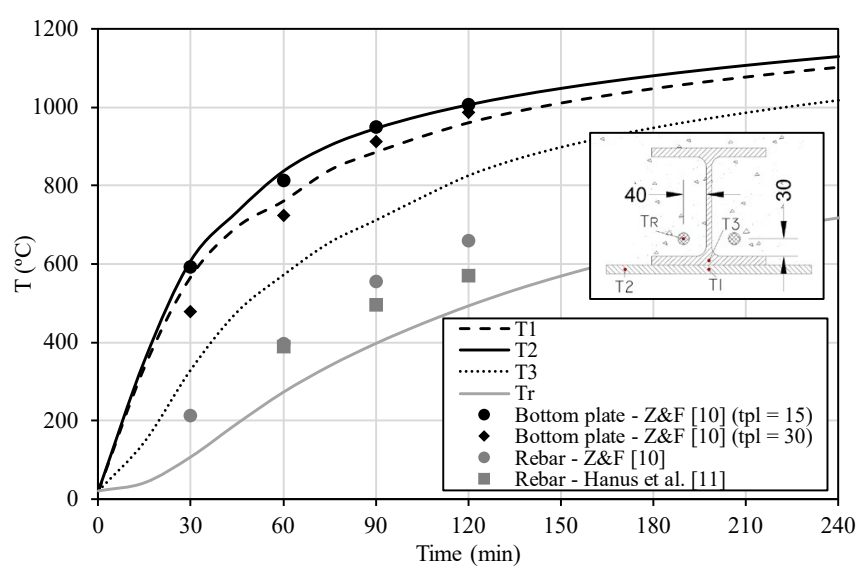

Fig. 5 Comparison of temperatures between FEM and simplified thermal model.

The results of this comparison show that the bottom plate simplified formula developed by Zaharia and Franssen [13] provides accurate results when compared with the temperature in point T1 and T2 from the FE model, see Fig. 5. The formula has been applied for $15 \mathrm{~mm}$ and 30 $\mathrm{mm}$ bottom plate thickness in order to take into account the influence of the thickness of the bottom plate. Additionally, it should be highlighted that point T3, placed in the lower flange, shows a significant lower temperature. The reason of this difference comes from the previously described thermal gap, which appears between the bottom plate (T1) and lower flange (T3) in SFB cross-sections [8].

Apart from the temperatures of the steel profile, the reinforcing bars temperature (Tr) has also been assessed. As can be seen, both Zaharia and Franssen [13] and Hanus et al. [14] models provide higher temperature than that obtained through the FE model. This finding was already noticed by Cajot, L.G et al. [17]. However, the model from Hanus et al. [14] shows closer results for 90 and 120 minutes of fire exposure. It seems therefore clear that the usage of previous 
formulas results on safe predictions but slightly more precise ones may be useful for the reinforcing bars temperature assessment.

Additionally, the comparison of temperatures along the web profile (see Fig. 6) shows that Zaharia and Franssen [13] formula provides higher temperatures than the FE model. The temperature difference increases with the fire exposure time and it is higher in the top part of the web. Moreover, it should be noticed that temperatures under $400^{\circ} \mathrm{C}$ reduce slightly the modulus of elasticity but do not reduce the steel yield strength and therefore the differences observed in this range of temperatures are not highly significant.

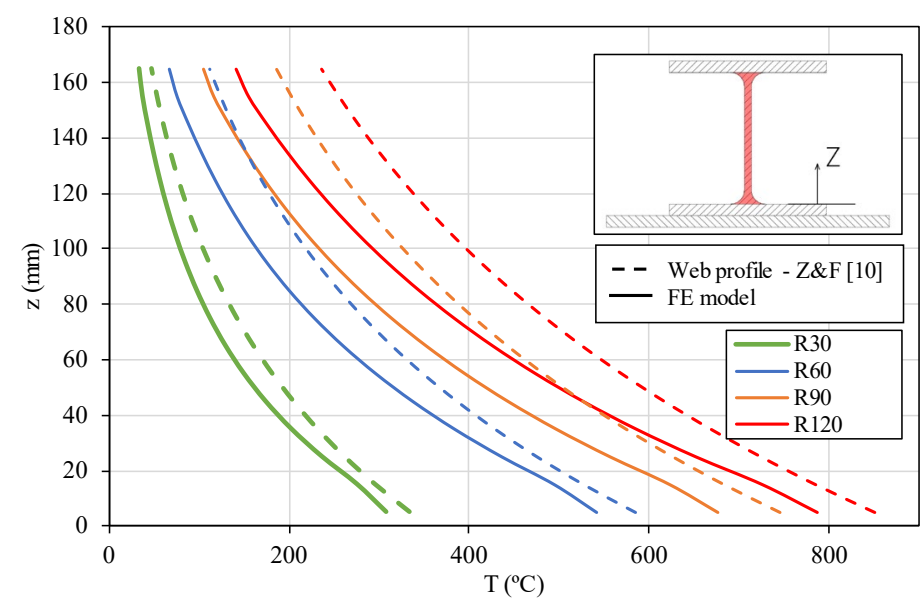

Fig. 6 Comparison of temperatures along the web of the steel profile.

The differences observed in the comparison of temperatures in the web of the steel profile may come from the fact that the previously described simplified formula [13] was developed for IFB cross-section configuration. However, the developed model shows the temperature field of a SFB. Therefore, the thermal gap described above, which apears between bottom plate and lower flange, may affect the temperature evolution along the web of the steel profile. In any case, the simplified model provides higher temperatures than the FE model.

\section{$4 \quad$ Worked example}

In this section, a worked example is presented to illustrate the calculation of the bending capacity of slim-floor beams in fire. Specifically, the process for obtaining the sagging moment resistance at elevated temperature is detailed herein.

According to EN 1994-1-2 [11], the fire resistance of a structural member for a certain fire exposure time $t$ is verified by checking that: 


$$
E_{f i, d, t} \leq R_{f i, d, t}
$$

where $E_{f i, d, t}$ is the design effect of the loads in the fire situation and $R_{f i, d, t}$ is the corresponding design resistance. This expression must be verified for the relevant duration of fire exposure which would be defined in the project for the structural member under evaluation.

This worked example is focused only on determining the design resistance of a slim-floor beam in the fire situation $R_{f i, d, t}$. The effect of the loads under fire conditions $E_{f i, d, t}$ depends on other project aspects which are out of the scope of this analysis.

Although it can only be achieved with lower load ratios, the fire exposure time in this worked example is considered as 120 minutes of standard time-temperature curve. The procedure would be exactly equal for other exposure times.

Once the general context of the analysis has been defined, the assessment of the slim-floor beam fire resistance is focused on the evaluation of the sagging bending moment capacity after 120 minutes, $R_{f i, d, t}=M_{f i, R d, 120}$.

The section analysed in this worked example is a SFB configuration composed of a HEB200 steel profile welded to a bottom plate of $15 \mathrm{~mm}$ thickness. Cross-sectional details are displayed in Fig. 7.

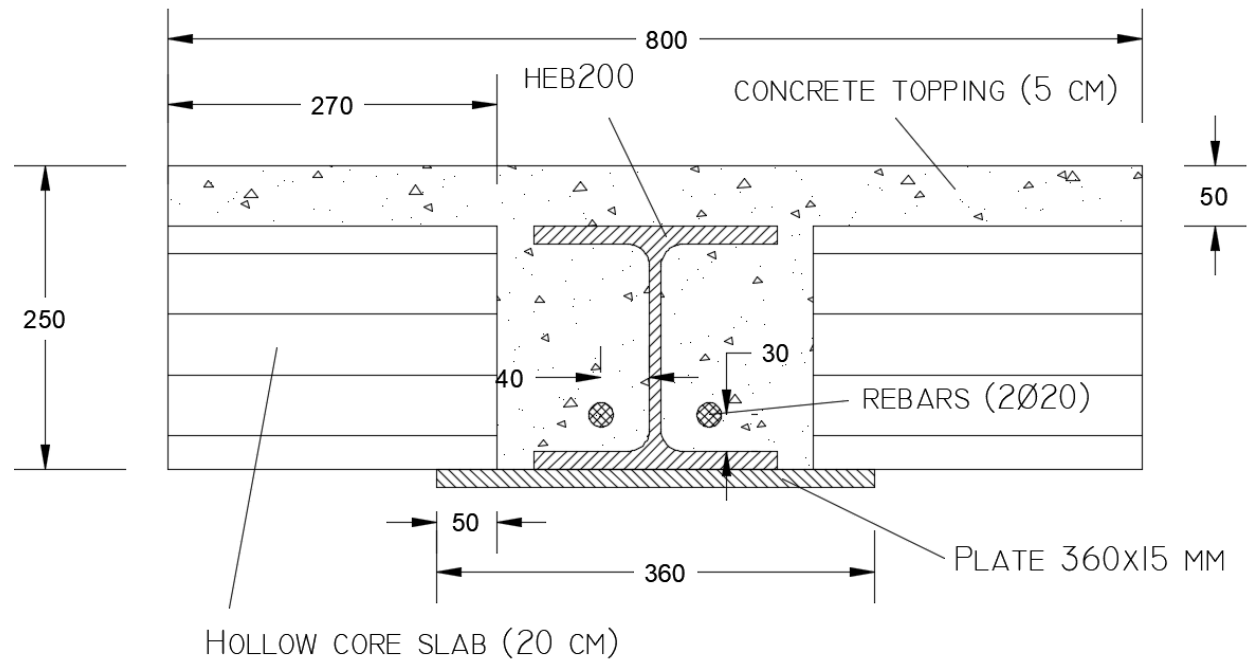

Fig. 7 Cross-sectional dimensions of the SFB used in the worked example .

In this example, the following values for the material strengths are considered:

- Steel profile and bottom plate: $f_{y}=355 \mathrm{MPa}$

- Concrete: $f_{c}=30 \mathrm{MPa}$

- Reinforcing bars: $f_{s}=500 \mathrm{MPa}$ 
To begin with the calculation process, the temperature of each cross-section part should be determined on a first instance. For that purpose, the simplified model from Zaharia and Franssen [13] is used. Additionally, the model from Hanus et al. [14] is also applied for obtaining the temperature of the reinforcing bars. In this calculation, any positive effect of the thermal gap between bottom plate and lower flange is neglected.

Specifically, the slim-floor beam cross-section is divided into 8 parts, see Fig. 8. Part 1 considers the lower flange of the steel profile and a portion of the bottom plate with the same width. Therefore, the thickness of part 1 is $30 \mathrm{~mm}$ in this example. In turn, part 2 comprises the rest of the bottom plate, which is $15 \mathrm{~mm}$ thick.

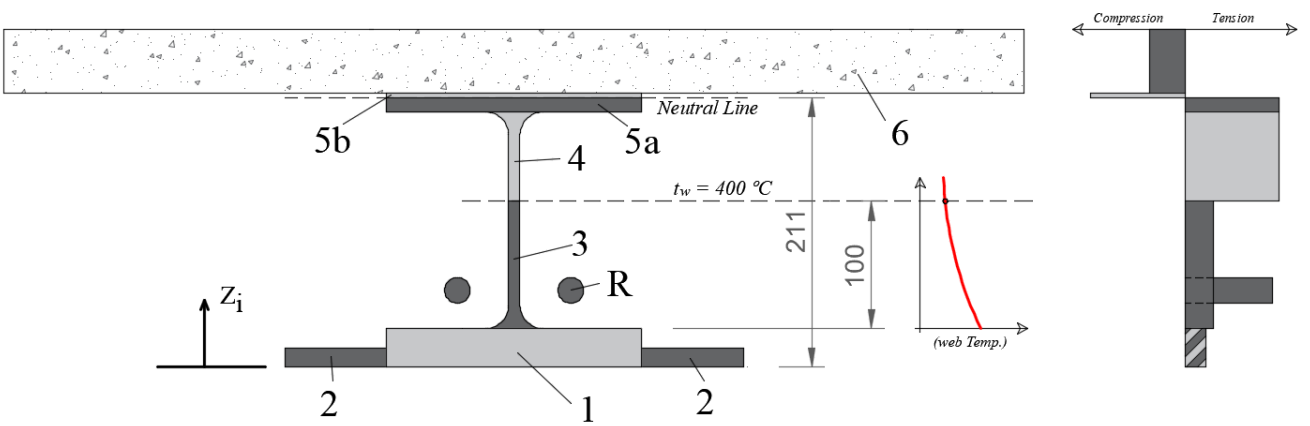

Fig. 8 Sub-division of the SFB cross-section into parts.

Regarding the web of the steel profile, it is divided into two parts: part 3, where the temperature remains over $400^{\circ} \mathrm{C}$ after 120 minutes of standard fire exposure, and part 4 , which is below $400^{\circ} \mathrm{C}$. This temperature limit is defined based on the fact that the structural steel yield strength is unaffected under $400^{\circ} \mathrm{C}$ according to EN 1994-1-2 [11]. The $400^{\circ} \mathrm{C}$ isotherm, see Fig. 8, is located $100 \mathrm{~mm}$ over the lower flange of the steel profile according to Zaharia and Franssen [13] simplified model (eq. 2).

Finally, part 5 is the upper flange of the steel profile, while part 6 is the top concrete compression zone and the part denoted as $<R>$ comprises the longitudinal reinforcing bars embedded in concrete.

Once each cross-section part temperature $-\theta\left({ }^{\circ} \mathrm{C}\right)$ - is obtained from the previously described simplified models [13], [14] (see Table 2), the corresponding strength reduction factor $\mathrm{k}_{\theta}$ can be deduced from EN 1994-1-2 [11].

By doing so, the resultant force at elevated temperature for each cross-section part can be calculated as follows: 


$$
F_{i, \theta}=A_{i} k_{i, \theta} f_{i}
$$

It should be highlighted that Zaharia and Franssen model [13], as it was described in previous section, provide specific temperature values for bottom plate and reinforcing bars. However, the web profile temperature is provided as a temperature function along the web. In this case, the temperature for the part 3 , the web over $400^{\circ} \mathrm{C}$, was assumed as the average value of this temperature evolution.

Table 2 Cross-section part data

\begin{tabular}{cccccccc}
\hline Part & $\begin{array}{c}\text { Area } \\
\mathrm{A}\left(\mathrm{mm}^{2}\right)\end{array}$ & $\begin{array}{c}\text { Temp. } \\
\theta\left({ }^{\circ} \mathrm{C}\right)\end{array}$ & $\begin{array}{c}\mathbf{f} \\
(\mathrm{MPa})\end{array}$ & $\mathbf{k}_{\boldsymbol{\theta}}$ & $\begin{array}{c}\mathbf{k}_{\boldsymbol{\theta}} \cdot \mathbf{f} \\
(\mathrm{MPa})\end{array}$ & $\begin{array}{c}\text { Force } \\
(\mathrm{kN})\end{array}$ & $\begin{array}{c}\mathbf{z}_{\mathbf{i}} \\
(\mathrm{mm})\end{array}$ \\
\hline 1 & 6000 & 987.5 & & 0.0425 & 15.09 & 90.53 & 15.0 \\
2 & 2400 & 1006.3 & & 0.0388 & 13.76 & 33.02 & 7.5 \\
3 & 900 & 642.2 & 355 & 0.360 & 130.90 & 117.8 & 72.5 \\
4 & 630 & $<400$ & & 1.0 & 355 & 223.65 & 157.5 \\
$5 \mathrm{a}$ & 2288 & $<400$ & & 1.0 & 355 & 812.30 & 205.7 \\
$5 \mathrm{~b}$ & 712 & $<400$ & & 1.0 & 355 & -252.70 & 213.2 \\
6 & 40000 & - & 30 & 1.0 & 30 & -1200 & 240 \\
$\mathrm{R}$ & 628.32 & $571.5^{*}$ & 500 & 0.558 & 279.18 & 175.41 & 60 \\
\hline * Obtained
\end{tabular}

The plastic neutral axis position can be obtained by using the equilibrium equation:

$$
\sum_{i} F_{i, \theta}=0
$$

It can be observed that, after some iterations, the plastic neutral axis in this worked example lies within the steel profile upper flange, exactly at $211.44 \mathrm{~mm}$ from the bottom face of the slimfloor section, see Fig. 8. Therefore, the upper flange should be divided into two parts (5a, 5b), in tension and compression, respectively. In addition, it should be highlighted that the effective width of the concrete compression part 6 depends on the beam length and it was obtained following EN 1994-1-1 [18] clause 5.4.1.2 (b $b_{\text {eff }}=800$ mm, see Fig. 8) assuming usual length in construction applications.

Moreover, it can be observed in Table 2 that the tensile force of bottom steel plate decreases dramatically after 120 minutes of fire exposure due to its high temperature. The main contribution to the tensile force is provided by the web of the steel profile and the reinforcing bars. Therefore, the plastic neutral axis moves upwards as the fire progressively affects the lower parts of the cross-section, causing an important reduction of the bending moment.

The sagging plastic bending moment at elevated temperature can be calculated by multiplying the resultant force of each part times the distance $\left(\mathrm{z}_{\mathrm{i}}\right)$ of its centroid measured from the bottom 
face.

$$
M_{f i, R d, 120}=\sum_{i} z_{i} F_{i, \theta}=118.9 m k N
$$

Additionally, the result obtained above can be compared with the advanced model developed by the authors, explained in detail in the previous section. Alternatively, Fig. 9 shows the crosssectional temperature field obtained by means of the finite element model. Besides, the computed stress distribution at elevated temperature is also indicated.
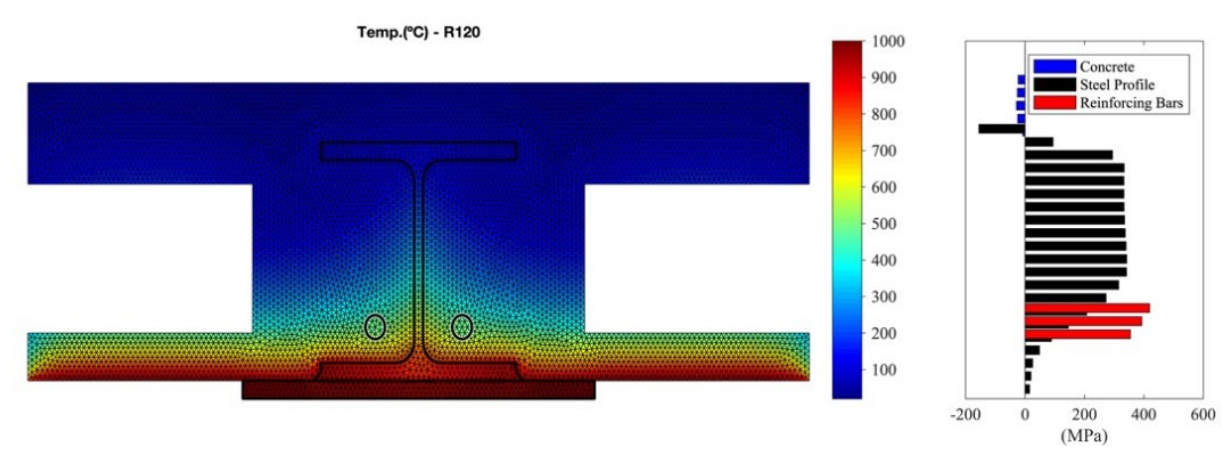

Fig. 9 Temperature and stress distribution from the developed numerical model

The sagging plastic bending moment obtained by means of the developed finite element model is $133.2 \mathrm{mkN}$, differing only a $9 \%$ from the result obtained by applying the simplified calculation method. The prediction of the simplified thermal model lies on the safe side, as the value obtained by hand calculation results lower than the more accurate one provided by the numerical model. The explanation of this safer response is attributed to the usage of the simplified temperatures derived from Zaharia and Franssen [13] and Hanus et al. [14] equations, which provide higher temperature predictions than the more realistic ones from the finite element model.

Knowing that the plastic bending moment resistance of this composite beam at room temperature is $656.1 \mathrm{mkN}$, the bending capacity obtained above after 120 minutes of standard fire exposure results in a low load ratio of $0.2 .$. However, the bending resistance for other fire exposure times can be obtained through the recurrent application of the advanced model, obtaining the evolution of the load ratio with the fire exposure, as given in Fig. 10. As can be seen, higher load ratios can be reached for lower fire exposure times, obtaining load ratios above 0.4 for fire periods shorter than 60 minutes. Additionally, the same configuration was assessed without longitudinal reinforcing bars (SFB-UNRE) and increasing the diameter of the reinforcing bars to $32 \mathrm{~mm}$ (SFB-RE(2fi32)). 


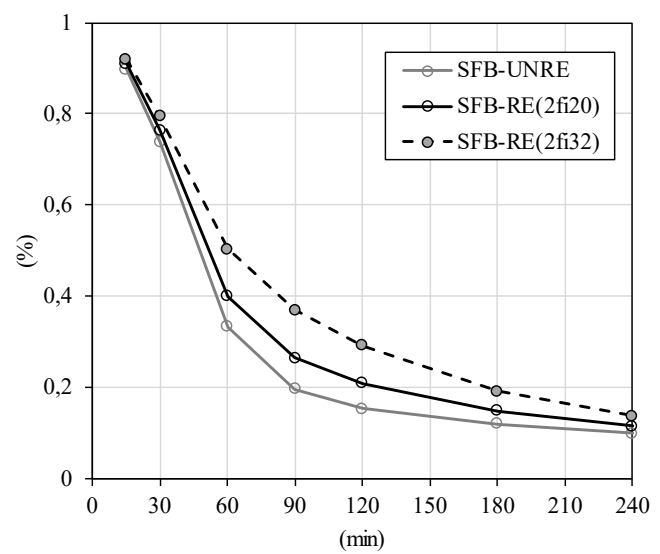

Fig. 10 Evolution of the SFB load ratio for different standard fire exposure times.

It can be noticed (see Fig. 10) that even with a dramatical increment of the reinforcing bars diameter, - note that a $32 \mathrm{~mm}$ diameter is not common in practice - , the fire resistance for moderate load ratios cannot achieve more than 90 minutes. Therefore, new innovative solutions should be developed to reach further increase of fire resistance.

\section{$5 \quad$ Current trends and future research}

Following the worked example presented above and the description of the available models exposed in previous sections, this part pretends to summarize the current knowledge on the fire performance of slim-floor beams, in order to help practitioners in their future designs. These guidelines are related to aspects like the better cross-section configuration to improve the composite beam fire resistance or the advisable usage of advanced materials such as stainless steel or lightweight concrete.

\section{- Thermal Gap}

The thermal gap, described previously for SFB, works as an insulation barrier to the heat flow conducted upwards along the web profile from the lower exposed surface. The thermal contact conductance, which appears at the contact interface between different materials or cross-section members, is a well-known phenomenon [19] that has been already studied in other structural elements like concrete-filled steel tubular (CFST) columns [20].

Recent experimental tests were also carried out by the authors [9] in the testing facilities of Universitat Politècnica de València, Spain, as part of a wider experimental campaign currently underway. These tests provided evidences about the different thermal behaviour between SFB and IFB due to the thermal contact resistance in the gap between the bottom plate and lower 
flange, proving the previous findings, see Fig. 11.

a)

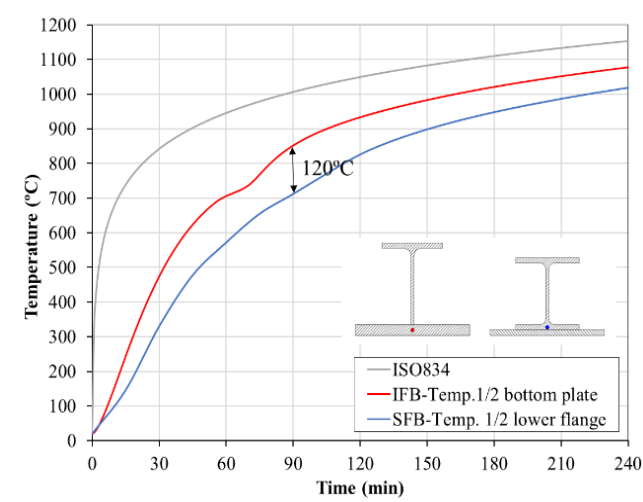

b)

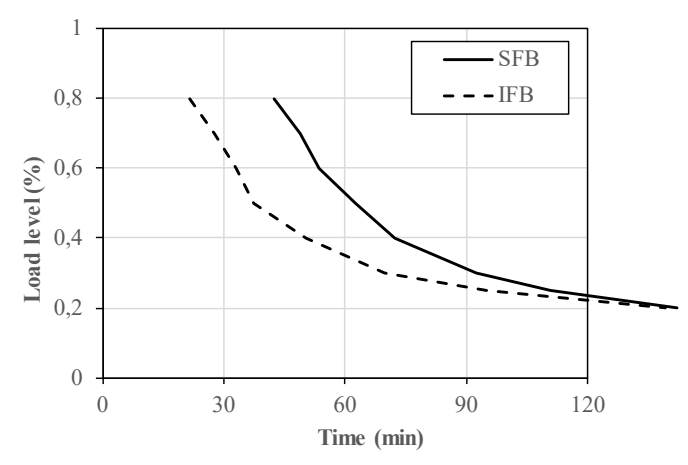

Fig. 11 Comparison of the fire performance between SFB and IFB configurations: a) Temperature difference [9]; b) Fire resistance difference [8].

\section{- High Strength Steel}

Advanced materials such as high strength steel (HSS) may be used to further increase the fire performance of slim-floor beams. Previous research work [21] has shown that in case of using high strength steel, it should be reserved to be placed in the steel profile rather than in the bottom plate, see Fig. 12. Its usage in the bottom plate does not provide a significant increase of the bending resistance, as it results directly exposed to fire and thus its strength is rapidly affected by high temperatures. Fig. 12 shows the evolution of the bending capacity under a standard fire for different locations of HSS in the SFB cross-section (Plate - Profile), supporting the previous findings. 


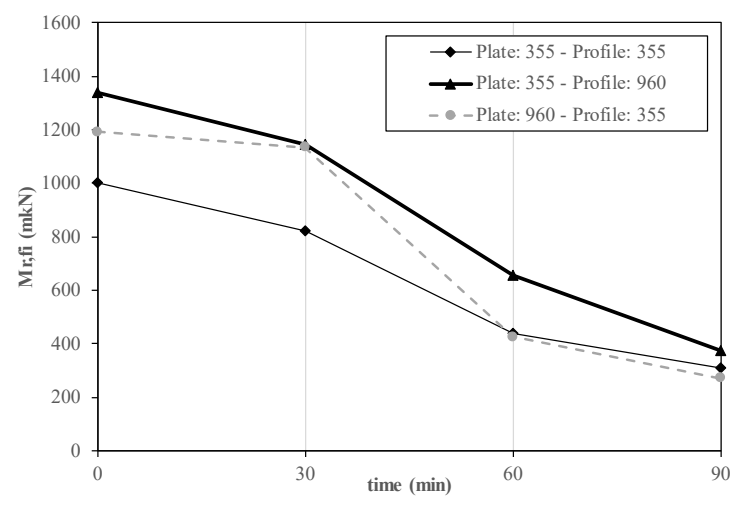

Fig. 12 Evolution of the ultimate bending moment under standard fire exposure, with different HSS combinations [21].

\section{- Lightweight Concrete}

The use of lightweight concrete in the slim-floor beam encasement has been also assessed in previous investigations [9] concluding that, for this typology of composite beam, the advantage provided by this type of concrete depends on the degree of reinforcement. The lower thermal conductivity of lightweight concrete and its consequent delay of the temperature rise in the concrete mass causes a localized temperature increase in the bottom steel plate and thus a reduction of its contribution to the bending moment capacity. In turn, lightweight concrete provides an additional heat insulation for the reinforcing bars and therefore increases their mechanical contribution in fire. Thus, in shallow floor beams configurations where the amount of reinforcement is significant, this additional protection offered by lightweight concrete may counteract the unfavourable effect of the reduction of strength of the bottom plate and help increasing the total bending capacity of the cross-section in fire.

\section{- Stainless Steel}

The performance of stainless steel under fire conditions has been assessed through extensive research over the last years [22], [23] showing a better strength retention at elevated temperatures and a lower emissivity which can delay the cross-section heating. Therefore, it seems a favorable material to be used in the bottom plate of slim-floor beams [24]. Apart from a better fire performance, it also provides an improved durability and an aesthetic finishing of the ceiling.

\section{- Composite action}

Finally, it should be highlighted that the composite action in slim-floor beams during fire may be guaranteed provided that an appropriate amount of shear connectors are placed in the cool 
cross-section zone. For instance, shear studs welded to the upper flange of the steel profile would be in a good position to be protected from fire action. Additionally, when slim-floor beams are used supporting precast units, the local bending moment of the bottom plate, which works as a cantilever in the transverse direction, should be checked. Specific reinforcing tie bars should be placed into the concrete encasement so as to work in the transverse direction.

\section{Concluding remarks}

The fire behavior of slim-floor beams has been reviewed in this paper, showing that these composite beams provide a good performance in the event of fire. Specifically, current slim-floor beam configurations can achieve 60 minutes of standard time-temperature curve exposure with a load level lower than $0.5-0.6$. It has been noticed that reaching the goal of 90 or even 120 minutes of fire exposure with these load levels may require the usage of advanced materials such as stainless steel at the exposed bottom plate of HSS at the inner profile, or alternatively increasing the reinforcing bars diameter or using external fire protection.

Moreover, it has been highlighted in this work that based on previous studies available in the literature, the SFB configuration can provide a better fire performance than IFB due to the thermal gap which appears between bottom plate and steel profile lower flange. Some authors have even suggested that this gap should be ensured during the steel beam manufacturing.

Finally, from the assessment of the current design guidance, it has been concluded that the application of the simplified formulas developed by Zaharia and Franssen [13] and Hanus et al. [14] provide accurate temperature results higher than others from advanced FE models. Therefore, they should be recommended in practice to predict the cross-sectional temperatures of slimfloor beams when exposed to the standard ISO-834 time-temperature curve. However, it is worth noting that these equations are no longer valid when external protection is used.

\section{References}

[1] Thor, J. (1991) "Fire resistant steel beam coacting with concrete" European Patent Specification. Publication number 0292449B1. 03.07.91 Bulletin 91/27. European Patent Office. Paris, France.

[2] Peikko Group Global. "DELTABEAM® Slim Floor Structure for open spaces". https://www.peikko.com/products/deltabeam-slim-floor-structures/overview/

[3] Newman, G.M. (1995) Fire resistance of slim floor beams. Journal of Constructional Steel Research 33(1-2):87-100.

[4] Constructalia. ArcelorMittal Europe Construction. CoSFB: Composite slim floor beams https://constructalia.arcelormittal.com/en/products/cosfb 
[5] Fellinger, J.H.H.; Twilt, T. (1996) Fire resistance of slim floor beams. Proceedings of the 2nd ASCE Conference. Irsee, Germany.

[6] Ma, Z; Mäkeläinen, P. (2000) Behavior of composite slim floor structures in fire. Journal of structural engineering 126:830-7.

[7] Lawson, R. M.; Mullet, D. L.; Rackham, J. W. (1997) Design of asymetric 'Slimflor' beams using deep composite decking. The Steel Construction Institute. Berkshire, U.K.: 1997.

[8] Albero, V.; Espinós, A.; Serra, E.; Romero, M. L.; Hospitaler, A. (2019) Numerical study on the flexural behaviour of slim-floor beams with hollow core slabs at elevated temperature. Engineering Structures 180, 561-573.

[9] Albero, V.; Espinos, A.; Serra, E.; Romero, M. L.; Hospitaler, A. (2018). Experimental study on the thermal behaviour of fire exposed slim-floor beams. In Proceedings of the 12th International Conference on Advances in Steel-Concrete Composite Structures, Valencia, Spain.

[10]CEN. EN 1991-1-2, Eurocode 1: Actions on structures. Part 1-2. General actions - actions on structures exposed to fire. In. Brussels, Belgium: Comité Européen de Normalisation, 2002.

[11]CEN. (2005) EN 1994-1-2, Eurocode 4: Design of composite steel and concrete structures. Part 1-2: General rules - Structural fire design. In. Brussels, Belgium: Comité Européen de Normalisation.

[12]Romero, M. L.; Cajot, L.-G.; Conan, Y.; Braun, M. (2015) Fire design methods for slimfloor structures. Steel Construction, 2015, 8(2), 102-109.

[13]Zaharia, R.; Franssen, J. M. (2012) Simple equations for the calculation of the temperature within the cross-section of slim floor beams under ISO Fire. Steel and Composite Structures 13(2), 171-185.

[14]Hanus, F.; Zaganelli, D.; Cajot, L.-G.; Braun, M. (2017). Analytical methods for the prediction of fire resistance of "reinforced" slim floor beams. In Proceedings of the EuroSteel 2017, Copenhagen, Denmark2017, E. SOHN ed.

[15]CEN. EN 1992-1-2, Eurocode 2: Design of concrete structures. Part 1-2: General rules Structural fire design. In. Brussels, Belgium: Comité Européen de Normalisation, 2004.

[16] Ellobody, E. (2011) Nonlinear behaviour of unprotected composite slim floor steel beams exposed to different fire conditions. Thin-Walled Structures 49:762-71.

[17] Cajot, L.-G.; Gallois, L.; Debruyckere, R.; Franssen, J. M. (2012). Simplified design method for slim floor beams exposed to fire. In Proceedings of the Nordic Steel Construction Conference, Oslo, Norway2012.

[18] CEN. EN 1994-1-1, Eurocode 4: Design of composite steel and concrete structures. Part 11: General rules and rules for buildings. In. Brussels, Belgium: Comité Européen de Normalisation, 2004.

[19] Cengel, Y.A.; Ghajar, A.J. Heat and Mass Transfer. Fundamentals \& Applications. Mc Graw Hill Ed. ISBN 978-0-07-339818-1. (Chapter 3-2)

[20]Espinos, A.; Romero, M. L.; Hospitaler, A. (2010) Advanced model for predicting the fire response of concrete filled tubular columns. Journal of Constructional Steel Research 66(89), 1030-1046.

[21]Espinos, A.; Albero, V.; Romero, M. L.; Hospitaler, A.; Ibáñez, C. (2017). Application of advanced materials for enhancing the fire performance of slim-floors. In Proceedings of the EuroSteel 2017, Copenhagen, Denmark2017, E. SOHN ed.

[22] Gardner, L.; Insausti, A.; Ng, K. T.; Ashraf, M. (2010) Elevated temperature material properties of stainless steel alloys. Journal of Constructional Steel Research 66(5), 634-647.

[23] Renaud, C. (2007) European Project RFS-04048 "Stainless Steel in Fire". Work Package 2: Composite members in fire. Final report. Centre Technique Industriel de la Construction Métallique.

[24]Ellobody, E. (2012) Composite slim floor stainless steel beam construction exposed to different fires. Engineering Structures 36, 1-13. 


\section{Autoren}

Prof Dr.-Ing. Manuel L. Romero

Instituto de Ciencia y Tecnología del Hormigón

Universitat Politècnica de València

Camino de Vera, s/n. 46022 Valencia, Spain

mromero@mes.upv.es

Dr.-Ing. Vicente Albero

Departamento de Ingeniería Mecánica y Construcción

Universitat Jaume I de Castelló

Av. de Vicente Sos Baynat, s/n. 12071 Castellón de la Plana, Spain valbero@uji.es

\section{Dr.-Ing. Ana Espinós}

Instituto de Ciencia y Tecnología del Hormigón

Universitat Politècnica de València

Camino de Vera, s/n. 46022 Valencia, Spain

aespinos@mes.upv.es

Prof Dr.-Ing. Antonio Hospitaler

Instituto de Ciencia y Tecnología del Hormigón

Universitat Politècnica de València

Camino de Vera, s/n. 46022 Valencia, Spain

ahospitaler@cst.upv.es 